\title{
To see in different seas: spatial variation in the rhodopsin gene of the sand goby (Pomatoschistus minutus)
}

\author{
MAARTEN H. D. LARMUSEAU, * JOOST A. M. RAEYMAEKERS, ${ }^{*}$ KEVIN G. RUDDICK,† \\ JEROEN K. J. VAN HOUDT $\ddagger$ and FILIP A. M. VOLCKAERT* \\ *Laboratory of Animal Diversity and Systematics, Katholieke Universiteit Leuven (K.U. Leuven), Ch. Deberiotstraat 32, B-3000 \\ Leuven, Belgium, +Management Unit of the North Sea Mathematical Models (MUMM), Royal Belgian Institute for Natural \\ Sciences (RBINS), 100 Gulledelle, B-1200 Brussels, Belgium, $¥$ Royal Museum for Central Africa, Leuvensesteenweg 12, B-3080 \\ Terouren, Belgium
}

\begin{abstract}
Aquatic organisms living in a range of photic environments require specific mechanisms to tune their visual pigments. Maximum absorbance $\left(\lambda_{\max }\right)$ of retinal rods in populations of the marine demersal sand goby, (Pomatoschistus minutus; Gobiidae, Teleostei) correlates with the local optic environment. It has been shown that this is not regulated through a physiological response by exchanging the rhodopsin chromophore. To test for evolutionary adaptation, the sequence of the rhodopsin (RH1) gene was analysed in 165 Pomatoschistus minutus individuals from seven populations across its distribution range. Analysis showed a high level of intraspecific polymorphism at the RH1 gene, including nonsynonymous mutations on amino acids, known as spectral tuning sites. Population differentiation at these sites was in agreement with the observed differentiation in $\lambda_{\max }$ values. Analyses of $d_{\mathrm{N}} / d_{\mathrm{S}}$ substitution rate ratios and likelihood ratio tests under site-specific models detected a significant signal of positive Darwinian selection on the RH1 gene. A strong discrepancy in differentiation was noticed between $R H 1$ gene variation and the presumably neutral microsatellites and mitochondrial data. Samples did not cluster according to geographical or historical proximity with regards to $\mathrm{RH1}$, but according to the general photic conditions of the habitat environment of the sand goby. This study highlights the usefulness of sensory genes, like rhodopsin, for studying the characteristics of local adaptation in marine nonmodel organisms.
\end{abstract}

Keywords: adaptive evolution, candidate gene, Gobiidae, marine fish, photoreceptor, remote sensing, vision

Received 29 July 2008; revision received 26 March 2009; accepted 18 April 2009

\section{Introduction}

For too long, the genetic structure of marine organisms has been thought to be homogeneous because of the lack of obvious barriers to gene flow in the environment. As gene flow is expected to hamper adaptive population divergence, the traditional idea was that local adaptation may be rare or absent in marine fishes (Hemmer-Hansen et al. 2007). Lately, however, an

Correspondence: Maarten H. D. Larmuseau,

Fax: +32 16324575; E-mail: maarten.larmuseau@bio.kuleuven.be increasing number of population genetic studies have described complex genetic structures in several marine species (Knutsen et al. 2003; Pampoulie et al. 2008). One major factor responsible for the present genetic structure of marine species is the geological and climatological history during the Pleistocene glaciations (Debes et al. 2008; Luttikhuizen et al. 2008). Also contemporary factors maintain and promote genetic differentiation among marine populations on various geographical scales. The marine environment shows heterogeneity in response to climate, hydrodynamics and topography (Cowen et al. 2000), and biological traits, such as 
sex-dependent migration, site philopatry and assortative mating enhance genetic structuring (Ruzzante et al. 1998). Stable neutral genetic structuring among populations may indicate that local selection is overriding the effects of drift and gene flow, resulting in adaptive divergence. Local adaptation in marine organisms has become increasingly documented, indicating that selection is also a potent evolutionary force in the marine environment (Canino et al. 2005; Hemmer-Hansen et al. 2007; Zane 2007; Sherman \& Ayre 2008). Nevertheless, knowledge of the spatial and temporal scale of adaptive genetic variation in marine systems remains scant, yet crucial to improve our understanding of how evolution operates in the ocean (Conover et al. 2006).

The sand goby, Pomatoschistus minutus (Pallas 1770; Gobiidae, Teleostei) is a common small marine demer- sal fish inhabiting the shallow waters along European coasts (Miller 1986; Fig. 1). A recent study has shown relatively low levels of gene flow and high genetic structuring in this species compared with other marine fish species (Larmuseau et al. 2009). Therefore, it is a suitable model for studying the characteristics of local adaptation in the marine environment. Middle Pleistocene glaciations yielded three isolated and differently evolving sets of sand goby populations. Reciprocal mitogenic monophyly was observed between a Mediterranean Sea (MS) and an Atlantic Ocean (AO) Clade (Larmuseau et al. 2009). The AO-Clade contains two major phylogeographic groups: the Iberian Peninsula (IB) group and the North Atlantic (NA) group. For the NA-Group, there is evidence for geographic sorting of the ancestral mitochondrial DNA (mtDNA) haplotypes

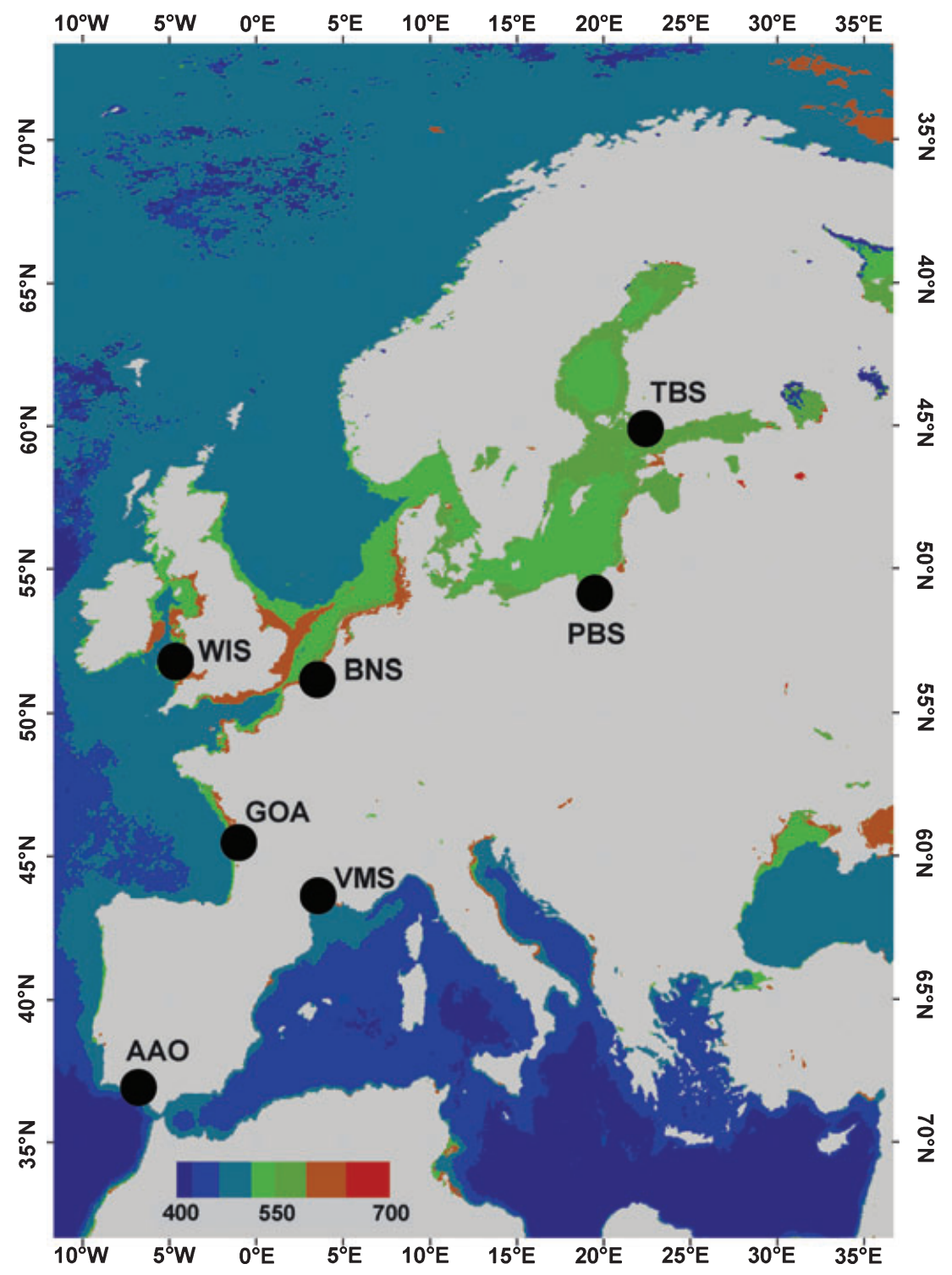

Fig. 1 Geographical distribution of the seven sampling locations in seven European marine systems for sand goby, $P o-$ matoschistus minutus. The wavelength $(\mathrm{nm})$ of maximally transmitted light estimated from the MODIS annual composite radiance data of 2007 is shown for all European seas. Discrete colours correspond to the MODIS wavelengths $412 \mathrm{~nm}$ (deep blue), $443 \mathrm{~nm}$ (blue), $488 \mathrm{~nm}$ (pale blue), $531 \mathrm{~nm}$ (bright green), $551 \mathrm{~nm}$ (dark green), $667 \mathrm{~nm}$ (red) and the default value $615 \mathrm{~nm}$ (orange) substituted in case of saturated data at 531,555 or $667 \mathrm{~nm}$. 
with recent radiations in the Baltic Sea, Irish Sea, North Sea and Bay of Biscay. Northern Baltic Sea sand gobies are considered to belong to an isolated population with clear evidence for founder effects (Larmuseau et al. 2009). Allozyme and microsatellite analyses largely corroborated this phylogeographic pattern (Stefanni et al. 2003; M. H. D. Larmuseau, unpublished data).

Sand gobies are visual feeders (Healey 1971; Aarnio \& Bonsdorff 1993) and mostly nocturnal. Patterns of activity are largely influenced by tides and light intensity (Ehrenberg \& Ejdung 2008). For P. minutus, nocturnal foraging is advantageous in approaching prey and in avoiding predators (Thetmeyer 1997). Relative to body size, the protruding eyes are large and might be capable of detecting prey organisms in very dim light (Thetmeyer 1997). The geographical distribution of the sand goby includes a wide range of photic environments, varying in turbidity, colour and brightness. Therefore, adaptation to the local spectral environment may be crucial. Vertebrates have visual pigment (VP) molecules bound in dense membrane stacks in retinal photoreceptors to mediate vision. The VP protein moiety is opsin, which is a G protein-linked receptor, bound to a light-sensitive chromophore, 11-cis retinal (A1) or 11-cis 3, 4-dehydroretinal (A2) (Park et al. 2008). Each pigment shows a characteristic peak of maximal absorbance $\left(\lambda_{\max }\right)$, its precise location depending on the interactions between the chromophore and the opsin protein. The pigment that mediates vision in dim light and absorbs light with $\lambda_{\max }$ of about $500 \mathrm{~nm}$, is rhodopsin; It is located in rod cells.

Vertebrates have various possibilities to modify their visual system to cope with the photic environment. The spectral tuning of the VP proteins can be assessed on a physiologically time scale through exchange of the chromophore (A1 or A2), consistent with an anticipated change in photic environment (Bowmaker 1995). Tuning can also be achieved at the DNA level on an evolutionary time scale through amino acid (AA) substitutions in the protein part (the opsin) (Yokoyama 2000). The first possibility seems unlikely in sand gobies. Jokela et al. (2003) measured the absorbance spectra microspectophotometrically in retinal rods of various sand goby populations. They found considerable variation in $\lambda_{\max }$ values within and between populations. The shapes of the absorbance spectra-indicated polymorphism at the rhodopsin gene rather than admixture of $\mathrm{A} 1$ and $\mathrm{A} 2$ chromophores, suggesting that the variation in $\lambda_{\max }$ values is genetic. Therefore, evolutionary adaptation, rather than physiological change, is presumed to be responsible for spectral tuning.

The tuning mechanism of VPs should be a suitable candidate to understand the opportunities and characteristics of local adaptation in the marine environment.
The aim of this study was to assess if sand gobies are evolutionary adapted to local photic environments on the rhodopsin gene (RH1). Our strategy to demonstrate local adaptation on RH1 consists of three steps: first, we demonstrate differentiation in the functional variation of the RH1 gene between sand goby populations. Next, we demonstrate that the population differentiation of RH1 is the result of selection. Finally, we establish a link between the functional variation of $R H 1$ and selection regimes.

\section{Materials and methods}

\section{Sampling and species identification}

A total of 165 Pomatoschistus minutus individuals were caught at seven locations along the European coast between January 2006 and February 2007 (Table 1, Fig. 1). Samples were taken either by fyke, hand net or beam trawling. The sand gobies were distinguished from other cryptic Pomatoschistus species morphologically, based on the dermal head papillae (Miller 1986) and pigmentation pattern (Hamerlynck 1990), and genetically, based on a polymerase chain reaction (PCR)-restriction fragment length polymorphism species identification protocol developed by Larmuseau et al. (2008).

\section{Gene amplification and sequencing}

Genomic DNA was extracted from fin clips, stored in $100 \%$ ethanol, using the NucleoSplin Extraction Kit (Machery-Nagel GmBH). An $868 \mathrm{bp}$ fragment of the RH1 gene was amplified in PCR with the forward primer PminRh1F GCGCCTACATGTTCTTCCTT and the reverse primer Rh1039r TGCTTGTTCATGCAGATGTAGA (Chen et al. 2003). The forward primer was designed using the Primer 3 program (Rozen \& Skaletsky 1998) on conserved regions of the alignment of RH1 gene sequences from P. minutus (Acc no. X62405), Gobius niger (Y18675), Zeus faber (Y14484), Sargocentron diadema (U57537) and Sargocentron microstoma (U57542). Developing new primers to amplify a larger fragment of the RH1 gene was not successful because of coamplification of other opsin genes. PCR reactions were carried out on a GeneAmp PCR System 2700 thermocycler (Applied Biosystems) in a total volume of $25 \mu \mathrm{L}$, containing $1 \mu \mathrm{L}$ of genomic DNA, 1X PCR buffer, $0.2 \mathrm{~mm}$ dNTPs, $0.8 \mu \mathrm{M}$ of each primer, $2.0 \mathrm{~mm} \mathrm{MgCl}_{2}$, $0.5 \mathrm{U}$ of Taq DNA polymerase (Silverstar; Eurogentec) and $\mathrm{mQ}-\mathrm{H}_{2} \mathrm{O}$. The PCR profile was: $4 \mathrm{~min}$ at $94{ }^{\circ} \mathrm{C}$ followed by 35 cycles of $30 \mathrm{~s}$ at $96{ }^{\circ} \mathrm{C}, 30 \mathrm{~s}$ at $54{ }^{\circ} \mathrm{C}$ and $1 \mathrm{~min}$ at $72{ }^{\circ} \mathrm{C}$; with a final 10 -min extension at $72{ }^{\circ} \mathrm{C}$. To avoid contamination, different pipettes, aerosol 
Table 1 Collection information for the seven populations of Pomatoschistus minutus, including code, marine system, country, site, date, longitude and latitude and sample sizes for the RH1 and microsatellite analyses $\left(N_{\mathrm{r}}\right.$ and $N_{\mathrm{s}}$ respectively)

\begin{tabular}{|c|c|c|c|c|c|c|c|c|}
\hline Code & Marine system & Country & Site & Date & Latitude & Longitude & $N_{\mathrm{r}}$ & $N_{\mathrm{s}}$ \\
\hline TBS & (Northern) Baltic Sea & Finland & Tvärminne & $\mathrm{Jul} / 2006$ & $59^{\circ} 50^{\prime} \mathrm{N}$ & $23^{\circ} 12^{\prime} \mathrm{E}$ & 20 & 96 \\
\hline PBS & (Southern) Baltic Sea & Polen & Sopot, Bay of Gdańsk & $\mathrm{Feb} / 2007$ & $54^{\circ} 27^{\prime} \mathrm{N}$ & $18^{\circ} 35^{\prime} \mathrm{E}$ & 10 & - \\
\hline BNS & North Sea & Belgium & Oostduinkerke & Nov/2006 & $51^{\circ} 08^{\prime} \mathrm{N}$ & $02^{\circ} 40^{\prime} \mathrm{E}$ & 27 & 47 \\
\hline WIS & Irish Sea & UK (Wales) & Llanfairfechan & Nov/2006 & $53^{\circ} 20^{\prime} \mathrm{N}$ & $03^{\circ} 59^{\prime} \mathrm{W}$ & 21 & 45 \\
\hline GOA & Atlantic Ocean (Bay of Biscay) & France & Gironde estuary & Aug/2006 & $45^{\circ} 36^{\prime} \mathrm{N}$ & $01^{\circ} 01^{\prime} \mathrm{W}$ & 22 & 40 \\
\hline $\mathrm{AAO}$ & Atlantic Ocean (Iberian Peninsula) & Spain & Guadalquivir river estuary & Nov/2006 & $36^{\circ} 58^{\prime} \mathrm{N}$ & $06^{\circ} 10^{\prime} \mathrm{W}$ & 37 & 95 \\
\hline VMS & Western Mediterranean Sea & France & Vaccarès lagoon & $\mathrm{Jan} / 2006$ & $43^{\circ} 32^{\prime} \mathrm{N}$ & $04^{\circ} 35^{\prime} \mathrm{E}$ & 28 & 94 \\
\hline
\end{tabular}

barrier tips and different sections of the laboratory were used for pre- and post-PCR work. In every other 15th individual (corresponding with one every two rows of a PCR-plate), a negative control was inserted to detect contamination. No contamination occurred during the screening procedures. All PCR products were visualized on agarose gels with ethidium bromide. After purification with the 'GFX PCR DNA and Gel Band Purification kit' (GE Healthcare), the PCR products were sequenced in both directions using the BigDye Terminator v. 3.1 Cycle Sequencing Kit on an ABI 3130 automated capillary DNA sequencer (Applied Biosystems). Sequences of $756 \mathrm{bp}$ (252 AA) were checked and aligned to each other with SEQSCAPE v. 2.1 (Applied Biosystems). The full rhodopsin sequence of $P$. minutus counts $1056 \mathrm{bp}$ and thus 352 AAs (Archer et al. 1992). The $252 \mathrm{AA}^{\prime}$ fragment under study thus represents $72 \%$ of the protein. However, all known 25 AAs involved in the spectral tuning of the VPs are included in this gene fragment (Yokoyama et al. 2007 and references herein). Automated detection of point mutations was realized with the GAP4 subprogram embedded in the STADEN package (http://sourceforge.net/projects/staden) and checked manually by eye.

For several reasons, we are convinced that no other member of the opsin gene family than the RH1 gene was co-amplified and analysed. First, when designing primers for rhodopsin, sites were selected that differ among paralogous genes. Second, other opsin genes have introns, unlike the rhodopsin genes of bony fishes (Bowmaker 1995). Third, the duplication event separating rhodopsin from other opsin genes occurred before the diversification of vertebrates (Yokoyama 2000). If we had sequenced by mistake, a paralogous opsin gene, the sequence alignment would have shown this extreme divergence. Finally, different PCR-products were cloned to control for a recent duplication event of the RH1 gene in P. minutus. A total of 21 individuals with more than one heterozygote single nucleotide polymorphism (SNP) locus was cloned into bacterial vectors using the TOPO-TA cloning kit (Invitrogen). Five to ten clones originating from two independent PCR reactions (for protocol see above) per specimen were sequenced. No more than two haplotypes were observed in each reaction, suggesting that only one gene was sequenced and analysed. All 38 rhodopsin haplotypes determined in this study were deposited in the GenBank database (Accession numbers: FJ410451-FJ410488; Table S1).

\section{Microsatellite genotyping and analysis}

Variation at eight high-quality microsatellite markers (Pmin03, Pmin04, Pmin09, Pmin16-2, Pmin29, Pmin31, Pmin35 and Pmin38) (Larmuseau et al. 2007) was assessed for 417 sand gobies of six populations (Table 1). Deviation from Hardy-Weinberg equilibrium and population differentiation quantified as $F_{\mathrm{ST}}$ were quantified with GENETIX v.4.05 (Belkhir et al. 2004).

\section{Haplotype reconstruction and network analysis}

Rhodopsin haplotypes of the 21 cloned individuals and 105 sequenced individuals with less than two heterozygous sites were available. The haplotypes of the 39 remaining individuals were inferred from the genotypes using the Bayesian statistical methods in the program PHASE v. 2.1 (Stephens et al. 2001; Stephens \& Donnelly 2003). Using this program, haplotypes have been resolved based on the assumption that unsolved haplotypes tend to be more similar to previously sampled known haplotypes. Runs were conducted separately for each population, with known haplotype information (i.e. homozygous haplotypes and cloned haplotypes) being included as prior information. Ten independent runs per population were conducted, each with a burnin-period of 1000 followed by 10000 iterations with a thinning interval of 100 steps. The results and the goodness-of-fit values were very similar among runs, indicating that the run lengths were sufficient. Haplotypes of individuals with more than one heterozygous site for which the phase could not be determined with a probability of $>95 \%$ (averaged over the ten runs) were 
excluded from the haplotype network (19 out of 165 analysed individuals). A haplotype network of the rhodopsin haplotypes was constructed using the statistical parsimony method implemented in the program TCS v. 1.21 (Clement et al. 2000). Interpopulation relationships were assessed by estimating pairwise $F_{\mathrm{ST}}$-values based on the haplotype distributions with Arlequin v. 3.11 (Excoffier et al. 2005). These values were then used for a classical multidimensional scaling (CMDS) analysis in the VEGAN package in $\mathrm{R}$ (Oksanen et al. 2007) for detecting group structure. CMDS plots having a stress value $<0.20$ provide interpretable information concerning intersite relationships (Clarke 1993).

\section{Genetic diversity and neutrality tests}

The number of segregating sites $(S)$, the mean number of pairwise differences $(k)$ and estimates of nucleotide polymorphism $(\pi, \theta)$ were calculated using DnaSP v. 4.10.9 (Rozas et al. 2003).

Several analyses were performed to determine if positive selection was involved in the evolution of RH1 in $P$. minutus. The number of synonymous substitutions per synonymous site $\left(d_{\mathrm{S}}\right)$ and the number of nonsynonymous substitutions per nonsynonymous site $\left(d_{N}\right)$ were estimated using the Z-test implemented in MEGA v. 4.0 (Tamura et al. 2007) according to Nei \& Gojobori (1986) with the correction of Jukes \& Cantor (1969) for multiple substitutions. The variances of $d_{\mathrm{S}}$ and $d_{\mathrm{N}}$ were computed by bootstrap (10 000 replicates). With this information, the null hypothesis of neutral evolution $\left(\mathrm{H}_{0}: d_{\mathrm{N}}=d_{\mathrm{S}}\right)$ vs. the hypothesis of positive selection $\left(\mathrm{H}_{1}: d_{\mathrm{N}}>d_{\mathrm{S}}\right)$ was tested using a Z-test: $Z=\left(d_{\mathrm{N}}-d_{\mathrm{S}}\right) / \operatorname{Sqrt}\left(\operatorname{Var}\left(d_{\mathrm{S}}\right)+\right.$ $\operatorname{Var}\left(d_{N}\right)$ ). The maximum-likelihood method (Yang et al. 2000) implemented in the program CODEML of the PAML 4.1 software package (Yang 2007) was used to test whether codon sites on the RH1 gene were affected by positive selection (Yang et al. 2005). The models were M7 (beta) and M8 (beta and $\omega$; Yang et al. 2000). While recombination can potentially generate false-positives in the detection of positive selection, these models are more robust against the occurrence of recombination than the other models implemented in CODEML (Anisimova et al. 2003). The models M7 and M8 are compared pairwise using the likelihood-ratio test (LRT; Nielsen \& Yang 1998). To provide phylogenetic information for the analysis, the best tree for $R H 1$ sequences was identified with the maximum likelihood method under the one-ratio model (M0) in CODEML. Positively selected codons ( $\omega>1$ with $P>95 \%$ ) were identified through an empirical Bayesian approach implemented in CODEML (Yang et al. 2005).

Another method used to test for the effects of differential selection among populations is to compare the distribution of the variation on $R H 1$ and neutral nuclear markers. If SNPs of the RH1 gene code for adaptive variation, the RH1 gene is expected to reveal aberrant population structures in comparison to nuclear markers (such as microsatellite markers), which may be behaving neutral (Bamshad \& Wooding 2003). To compare the degree of population differentiation between the RH1 and the microsatellite markers, several methods were applied. First, correlations between pairwise $F_{\mathrm{ST}^{-}}$ values of the two markers were calculated and tested using simple Mantel procedures (Mantel 1967) in the VEGAN package in $\mathrm{R}$ (Oksanen et al. 2007). Because the number of Mantel test permutations is limited for small sample sizes $(n=6)$ (Legendre 2000), complete enumeration of all possible $6 !=720$ permutations was carried out for all tests. Second, two-dimensional CMDS ordinations of pairwise $F_{\mathrm{ST}}$-values of different marker types were compared by a Procrustes Analysis (PA) (Gower 1975) with the VEGAN package. PA searches for the best match between two configurations of points in a multivariate Euclidean space using rotation, translation, reflection and dilation of one configuration. The criterion used to assess the best fit is the minimization of the sum of squares between the differences for each observation $\left(\mathrm{m}^{2}\right)$. The significance of the result, an optimal superposition of one configuration on the other (reference) configuration, is obtained through a permutation test (PROTEST, Jackson 1995). PROTEST uses $R=\operatorname{sqrt}\left(1-m^{2}\right)$ as a test statistic, which can be interpreted as a correlation. Finally, a selection detection workbench LOSITAN (Antao et al. 2008) based on the FDIST $F_{\mathrm{ST}}$ outlier methods of Beaumont \& Nichols (1996) was used to evaluate the neutrality of the microsatellites and the presumed outlier status of RH1. Different runs were assessed: one run with only microsatellite data, 14 different runs with all microsatellites and a polymorphic SNP of the RH1 gene, and a final run with all microsatellites and all polymorphic SNPs of the RH1 gene. For all runs 30000 simulations were generated with 'neutral mean $F_{\mathrm{ST}}$ ' and 'force mean $F_{\mathrm{ST}}$ ', to increase the reliability of the mean $F_{\mathrm{ST}}$.

\section{Environmental light measurements}

To correlate the differences in the rhodopsin gene variation between P.minutus populations with the light transmittance of the respective waters, the spectral distribution of environmental ambient light was measured in the northeastern Atlantic Ocean, Mediterranean Sea and adjacent seas. Lindström (2000) introduced the concept of 'wavelength of maximally transmitted light' (WMTL) to characterize the spectral content and depth variation of the underwater light climate by a single parameter for comparison with the spectral sensitivity 
of the eyes of marine animals. Whereas a combination of underwater light measurements and optical modelling is used by Audzijonyte et al. (2005) to estimate the WMTL at various locations, a new method is described in Appendix S1 to estimate this parameter from satellite remote sensing data. The method has the advantage of providing information at almost any location on earth without the need for in situ measurements or a priori knowledge, and of relying on a more uniform methodology. Water-leaving radiance data as measured by the MODIS-AQUA satellite sensor was downloaded on 19th November 2008 from the NASA 'Ocean Color' web site (http://oceancolor.gsfc.nasa.gov/) as the annual composite for 2007 (4-km standard map image file) for each of the available spectral bands (412, 443, $488,531,551$ and $667 \mathrm{~nm}$ ).

\section{Results}

\section{Nucleotide diversity of the RH1 gene}

Sequences matched the general properties of the Pomatoschistus minutus RH1 gene (X62405, Archer et al. 1992). In total, 19 segregating sites or SNPs were noticed across all genotypes (Table S2). Five SNPs (SNP $2,3,5,8$ and 18) were not polymorphic according to the $99 \%$ criterion; three polymorphic SNPs were part of the same codon and were merged (written further as SNP_9_10_11). The alignment in AA shows five nonsynonymous AA substitutions; four are located in the transmembrane helices and one in the C-II loop (Fig. 2). The sequencing and cloning reactions revealed 38 confidently resolved haplotypes (Table S1). Nucleotide diversity $(\pi)$ of the $R H 1$ gene fragment was estimated to be 0.0074 in total. The within-population RH1 nucleotide diversity values were highest in populations BNS, WIS and GOA (southern North Sea, Irish Sea and Bay of Biscay, respectively); the lowest value was found in PBS (southern Baltic Sea; Table 2).

\section{Population differentiation on the RH1 gene}

A maximum parsimony network of confidently resolved haplotypes revealed that three haplotypes are common in at least four populations (Fig. 3). Haplotype RhP7 is shared among all populations. Haplotypes clustered roughly into two groups, one containing the majority of haplotypes observed in the Iberian Peninsula, North Sea and Irish Sea, and another group containing haplotypes occurring mainly in the Mediterranean and Baltic Sea (Fig. 3). Accordingly, pairwise $F_{\mathrm{ST}}$-values (Table 3 ) showed a clustering of Mediterranean and northern Baltic Sea (VMS and TBS) samples; the Atlantic samples (GOA, WIS and AAO)

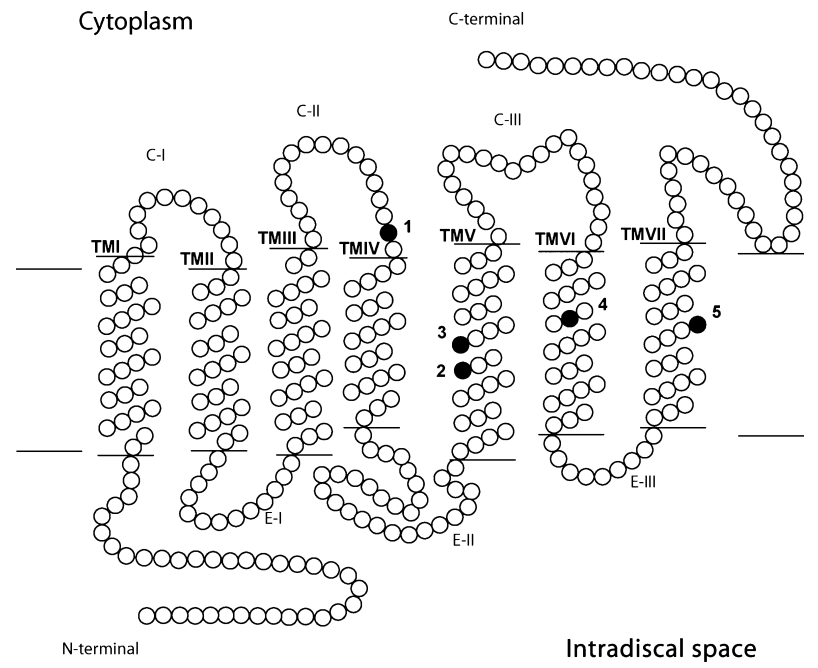

Fig. 2 Two-dimensional model of the seven transmembrane $\alpha$-helices of the bovine rhodopsin (RH1) as in Hargrave \& McDowell's (1992). The seven transmembrane helices (TM) are numbered, as well as the three loops at the cytoplasmic side (C) and the extracellular side (E) of the cell membrane. The different nonsynonymous mutations found in Pomatoschistus minutus are shown in filled circles. (1) AA151 (SNP4); (2) AA214 (SNP9_10_11); (3) AA217 (SNP12); (4) AA261 (SNP14); (5) AA299 (SNP19).

clustered together. Finally, the frequency of nonsynonymous SNPs and polymorphic AA differed between the populations (Table 4).

\section{Neutrality tests}

The null hypothesis of evolution according to the neutral model could not be rejected with a general Z-test for all samples combined as well as for the samples from the Baltic Sea, North Sea and Mediterranean Sea separately. The $d_{\mathrm{S}}$-values were significantly larger than the $d_{\mathrm{N}}$-values only for the Z-tests with the Atlantic samples WIS, GOA and AAO. However, the LRT of the maximum-likelihood analysis demonstrated that M8, the model that accounts for sites under positive selection, showed a significantly better fit than model M7, which does not allow for positive selection. The $\omega$ ratio is more than 1 (Table 5), indicating positive selection in the RH1 sequences of P. minutus. Bayes identification showed that sites AA151, 214 and 299 of the RH1 gene were significantly under positive selection.

Overall population differentiation was considerably higher for the full fragment of the RH1 gene $\left(F_{\mathrm{ST}}=0.4549\right)$ than at the nuclear microsatellite markers $\left(F_{\mathrm{ST}}=0.0126\right)$. Exact tests showed that no locus or sample exhibited consistent deviations from HardyWeinberg equilibrium with respect to microsatellites. The pairwise $F_{\mathrm{ST}}$-values of the $R H 1$ gene and the 


\begin{tabular}{|c|c|c|c|c|c|c|c|c|}
\hline \multirow[b]{2}{*}{ Population } & \multirow[b]{2}{*}{$N$} & \multicolumn{2}{|c|}{ No. haplotypes } & \multirow[b]{2}{*}{$S_{\mathrm{n}}$} & \multirow[b]{2}{*}{$S_{\mathrm{s}}$} & \multirow[b]{2}{*}{$k$} & \multirow[b]{2}{*}{$\pi$} & \multirow[b]{2}{*}{$\theta$} \\
\hline & & Total & Private & & & & & \\
\hline TBS & 20 & 8 & 2 & 5 & 3 & 1.763 & $0.0023 \pm 0.0015$ & 0.0028 \\
\hline PBS & 10 & 4 & 1 & 4 & 2 & 0.895 & $0.0012 \pm 0.0010$ & 0.0012 \\
\hline BNS & 27 & 14 & 8 & 5 & 8 & 4.197 & $0.0056 \pm 0.0006$ & 0.0038 \\
\hline WIS & 21 & 7 & 1 & 5 & 7 & 3.987 & $0.0053 \pm 0.0008$ & 0.0037 \\
\hline GOA & 22 & 8 & 4 & 4 & 6 & 3.755 & $0.0048 \pm 0.0007$ & 0.0030 \\
\hline $\mathrm{AAO}$ & 37 & 9 & 5 & 6 & 8 & 1.287 & $0.0017 \pm 0.0006$ & 0.0038 \\
\hline VMS & 28 & 12 & 6 & 4 & 4 & 1.449 & $0.0019 \pm 0.0003$ & 0.0023 \\
\hline Total & 165 & 38 & 27 & 6 & 13 & 5.608 & $0.0074 \pm 0.0001$ & 0.0039 \\
\hline
\end{tabular}

Table 2 Summary of diversity indices for the 19 polymorphic sites analysed for variation at the population level of the sand goby RH1 gene

$N$, number of individuals surveyed; $S_{n}$, number of nonsynonymous segregating sites; $S_{\mathrm{S}}$, number of synonymous segregating sites; $k$, mean number of pairwise differences; $\pi$, average number of nucleotide differences per site; $\theta$, theta per site. For site codes, see Table 1.

microsatellite data (Table 3) did not correlate with each other (Procrustes $R=0.218, \quad P$-value $=0.910$; Mantel $R=0.307, P$-value $=0.100$ ) (Table 6). Additionally, the simulation-based LOSITAN tests confirmed the neutrality of the microsatellites and the highly significant $>0.99$ ) outlier position of each SNP of the RH1 gene in comparison with the microsatellites (data not shown).

\section{Light measurements}

Figure 1 plots the broad spatial variation of the WMTL in the northeastern Atlantic Ocean and Mediterranean Sea. The default value of $615 \mathrm{~nm}$ (coloured in orange) was substituted in case of saturated data at 531, 555 or $667 \mathrm{~nm}$. This means that it is difficult to interpret the results along the coasts of Belgium, the Netherlands and the United Kingdom. The underwater light climate is mainly blue in the deep offshore oligotrophic waters of the Mediterranean and the Atlantic Ocean, west of the continental shelf break. Greener waters are found in the Southern North Sea, the southern Baltic Sea, near river mouths and in various shallow coastal waters in the North Sea, Mediterranean Sea and Black Sea. A few isolated areas with an underwater light climate shifted towards red light are found in nearshore regions of the northern Baltic Sea and for a few inland waters. The map therefore shows congruent, but more detailed results than previous maps of optical water types (Jerlov 1976).

\section{Discussion}

Functional polymorphism of the RH1 gene in Pomatoschistus minutus

Jokela et al. (2003) found individual differences in the $\lambda_{\max }$ values of the retinal rods of Pomatoschistus minutus. As the differences could not be explained by a chromo- phore change, they suggested polymorphism of the opsin gene instead of physiological changes. Sequence analysis revealed substantial variation at the $R H 1$ gene with 19 SNPs, of which 14 were polymorphic, in seven sand goby populations (Table S2). This is the first observation of such a high level of intraspecific variation at a spectral opsin gene in vertebrates. There are five AA replacements, of which some are known to have a significant effect on the $\lambda_{\max }$ values of retinal rods in aquatic vertebrates.

One of the AA substitutions present in sand goby is a phenylalanine to tyrosine substitution of AA261 (SNP14), known for causing a strong red-shift of the $\lambda_{\max }$ values in retinal rods of many teleost families (Hunt et al. 1996, 2001; Yokoyama \& Takenaka 2004). A comparative study on Salmonidae showed that the Phe261Tyr substitution causes a red-shift of ca. $10 \mathrm{~nm}$ in Salmo salar in comparison with Oncorhynchus sp. (Dann et al. 2004). A mutagenesis experiment of this mutant in Astyanax fasciatus confirmed a red-shift of $8 \mathrm{~nm}$ in $\lambda_{\max }$ values (Yokoyama et al. 1995). The second well known mutation is on AA299 (SNP19). This site is localized towards the interior of the retinal binding pocket in helix VII (Fig. 2) and close to the Schiff base linkage between the opsin and the chromophore (Hunt et al. 2007). It suggests that this AA directly interacts with the chromophore (Fasick \& Robinson 1998). A weak blue-shift of the $\lambda_{\max }$ values of retinal rods caused by the Ala299Ser/Thr substitution has already been documented in many teleost families (Yokoyama et al. 1995; Hunt et al. 2001) and in the bottlenose dolphin (Tursiops truncatus) (Fasick \& Robinson 1998).

Limited information is available for the three other AA-substitutions in the data set (AA151, AA214 and AA217). A comparative analysis of all available RH1 genes of Teleostei on GenBank showed that those three AA sites are not conserved in Teleostei (results not 


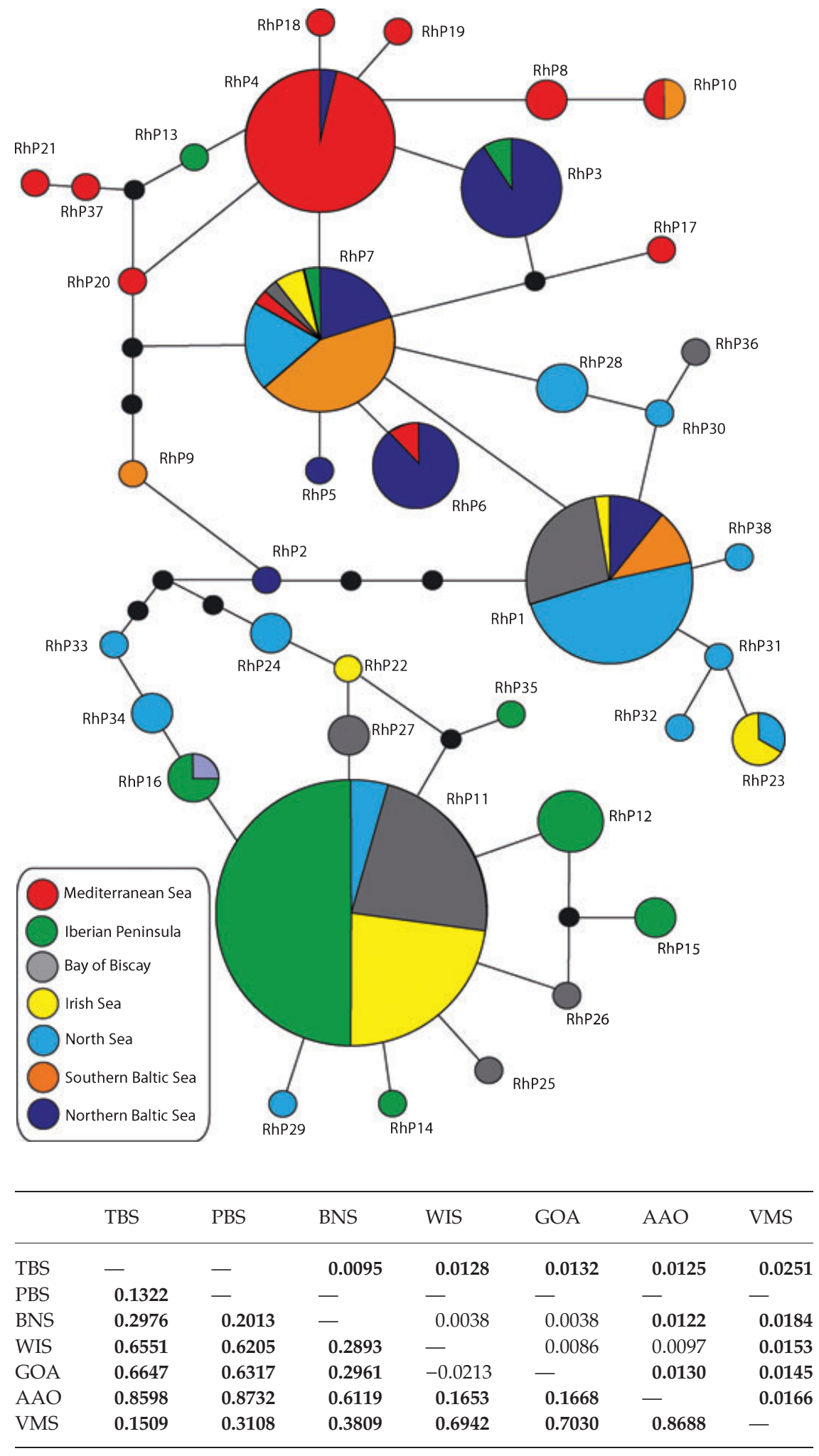

Fig. 3 Statistical parsimony network of the rhodopsin haplotypes of Pomatoschistus minutus. The size of the circles is proportional to the number of gobies sharing that haplotype. Haplotypes are indicated by numbers as given in Table S1. Black dots are undetected haplotypes.
Table 3 Pairwise $F_{\mathrm{ST}}$-estimates based on the RH1 gene (below diagonal) and based on the microsatellite loci (above diagonal) between sand goby populations (significant $P$-values after Bonferroni correction are in bold

For site codes, see Table 1.

shown). The effect on $\lambda_{\max }$ values of substituted AA214 and AA217 (SNP9_10_11 and SNP12, respectively) has been tested by mutagenesis experiments on red/green opsins (Yokoyama 2000). Only substitution Ile214Thr caused a substantial difference of $<5 \mathrm{~nm}$ from red to green in red/green opsins (Asenjo et al. 1994). How- 


\begin{tabular}{|c|c|c|c|c|c|c|c|}
\hline & \multicolumn{7}{|c|}{ Population } \\
\hline & TBS & PBS & BNS & WIS & GOA & $\mathrm{AAO}$ & VMS \\
\hline \multicolumn{8}{|c|}{ AA151 (or SNP4) } \\
\hline Asn & 0.125 & 0.250 & 0.741 & 0.929 & 0.977 & 0.960 & 0.107 \\
\hline Thr & 0.875 & 0.750 & 0.259 & 0.071 & 0.023 & 0.040 & 0.893 \\
\hline \multicolumn{8}{|c|}{ AA214 (or SNP9_10_11) } \\
\hline Ala & 0.975 & 0.950 & 0.704 & 0.286 & 0.273 & 0.040 & 0.893 \\
\hline Ile & 0.025 & 0.050 & 0.296 & 0.714 & 0.727 & 0.960 & 0 \\
\hline Thr & 0 & 0 & 0 & 0 & 0 & 0 & 0.107 \\
\hline \multicolumn{8}{|c|}{ AA217 (or SNP12) } \\
\hline Ile & 0.625 & 0.950 & 0.981 & 0.976 & 1 & 0.973 & 0.179 \\
\hline Thr & 0.375 & 0.050 & 0.019 & 0.024 & 0 & 0.027 & 0.821 \\
\hline \multicolumn{8}{|c|}{ AA261 (or SNP14) } \\
\hline Phe & 0.450 & 1 & 1 & 1 & 1 & 0.973 & 0.857 \\
\hline Tyr & 0.550 & 0 & 0 & 0 & 0 & 0.027 & 0.143 \\
\hline \multicolumn{8}{|c|}{ AA299 (or SNP19) } \\
\hline Ala & 1 & 1 & 0.667 & 0.238 & 0.250 & 0.054 & 1 \\
\hline Ser & 0 & 0 & 0.333 & 0.762 & 0.750 & 0.946 & 0 \\
\hline
\end{tabular}

Table 4 Frequency of the AA substitutions detected at the $R H 1$ gene in seven sand goby populations

The highest frequency in a population is given in bold for each AA. For site codes, see Table 1.

Table 5 Log-likelihood values and parameter estimates for the RH1 gene sequences of Pomatoschistus minutus

\begin{tabular}{|c|c|c|c|}
\hline Model & $\ln L$ & $\begin{array}{l}\text { Estimates of } \\
\text { paramaters }\end{array}$ & $\begin{array}{l}\text { Positively } \\
\text { selected sites }\end{array}$ \\
\hline M7 (beta) & -1361.766 & $\begin{aligned} P & =0.02286 \\
q & =0.14384\end{aligned}$ & \\
\hline M8 (beta \& $\omega)$ & -1337.268 & $\begin{aligned} q_{0} & =0.97818 \\
\left(P_{1}\right. & =0.02182) \\
P & =0.00500 \\
q & =0.27884 \\
\omega & =6.02381\end{aligned}$ & $\begin{array}{l}151^{* *} \\
214^{* *} \\
261 \\
299^{* *}\end{array}$ \\
\hline
\end{tabular}

$\ln L$ is the log-likelihood value, $\omega$ is the selection parameter and $P_{n}$ is the proportion of sites that fall into $\omega_{n}$ site class. Sites inferred to be under positive selection are given at the $99 \%$ (**) $^{* *}$ confidence interval level.

ever, the effect of a substitution on the AA214 in the rhodopsin gene remains unknown. AA151 (SNP4) is the only AA-substitution that is not located in the helix structure (Fig. 2), but may still affect $\lambda_{\max }$ values (Yokoyama et al. 2007). Mutagenic experiments on the RH1 gene are required to study the effect of these five nonsynonymous mutations on the $\lambda_{\max }$ values of retinal rods in P. minutus.

Network analysis of the significant RH1 haplotypes (Fig. 3) and the highly significant $F_{\mathrm{ST}}$-values (Table 3) revealed that variation at the $R H 1$ gene is not randomly distributed. Several populations are differentiated for several AA sites of RH1, including the two well known AA (AA261 and 299) that most probably influence the $\lambda_{\max }$ values of retinal rods (Table 4 ). The differentiation is consistent with the $\lambda_{\max }$ values on the retinal rods as measured by Jokela et al. (2003). North Sea and Atlantic samples have blue-shifted AA-substitutions instead of the red-shifted substitution in the northern Baltic Sea sample (TBS) (Table 4), consistent with the larger $\lambda_{\max }$ values in the northern Baltic Sea gobies compared with their Atlantic relatives.

Based on the wide rod $\lambda_{\max }$ distributions within sand goby populations, Jokela et al. (2003) suggested the presence of within-population polymorphism on the RH1 gene. AA variation on RH1, including on AA261 and AA299, is indeed polymorphic in various populations, demonstrating a genetic basis for within-population variation in spectral sensitivity (Table 4). The equal distribution of tyrosine and phenylalanine on AA261 (SNP14) in the northern Baltic individuals, can explain the particularly broad $\lambda_{\max }$ distribution spanning $5.7 \mathrm{~nm}$ of the spectrum in the population (Jokela et al. 2003).

\section{Population differentiation on RH1 due to selection}

Our results suggest that interpopulation allelic variation of the RH1 gene is linked to selection as opposed to neutral processes like genetic drift. The $d_{\mathrm{N}} / d_{\mathrm{S}}$ substitution rate ratios of the complete $R H 1$ fragment in $P$. minutus did not reveal selection. However, tests of neutrality are generally conservative because substitution rates are averaged across all amino-acid sites tested (Bamshad \& Wooding 2003). Consequently, analyses of $d_{\mathrm{N}} / d_{\mathrm{S}}$ ratios and likelihood ratio tests under site-specific models detected significant signal of positive Darwinian selection on the RH1 gene. Bayesian analysis identified 


\begin{tabular}{llllll}
\hline Baseline & Marker & Mantel & $P$-value Mantel & Procrustes $R$ & $P$-value Procrustes $R$ \\
\hline$\mu_{\text {sats }}$ & SNPsyn+non & 0.307 & 0.100 & 0.218 & 0.910 \\
& SNPsyn & 0.202 & 0.167 & 0.143 & 0.972 \\
& SNPnon & 0.428 & 0.053 & 0.245 & 0.919 \\
& SNP1 (s) & 0.087 & 0.315 & 0.158 & 0.916 \\
SNP4 (n) & 0.340 & 0.111 & 0.153 & 0.939 \\
SNP6 (s) & 0.188 & 0.197 & 0.174 & 0.946 \\
SNP7 (s) & 0.199 & 0.190 & 0.169 & 0.932 \\
SNP9 (n) & 0.240 & 0.152 & 0.601 & 0.092 \\
SNP10 (n) & 0.208 & 0.171 & 0.220 & 0.916 \\
SNP11 (s) & 0.208 & 0.172 & 0.221 & 0.894 \\
SNP12 (n) & 0.633 & $\mathbf{0 . 0 4 8}$ & 0.453 & 0.433 \\
SNP13 (s) & 0.175 & 0.242 & 0.112 & 0.977 \\
SNP14 (n) & 0.300 & 0.273 & 0.351 & 0.524 \\
SNP15 (s) & 0.012 & 0.395 & 0.400 & 0.410 \\
SNP16 (s) & 0.629 & 0.108 & 0.581 & 0.175 \\
SNP17 (s) & 0.184 & 0.237 & 0.288 & 0.753 \\
SNP19 (n) & 0.223 & 0.162 & 0.172 & 0.931 \\
\hline
\end{tabular}

Table 6 Summary of the Mantel tests and Procrustes analyses correlating pairwise $F_{\mathrm{ST}}$-values based on microsatellites markers vs. the RH1 gene in Pomatoschistus minutus

Significant $P$-values $(<0.05)$ are given in bold. $\mu_{\text {sats }}$ microsatellite markers; SNPsyn+non, all rhodopsin SNPs of the RH1 gene; SNPsyn, all synonymous SNPs of the RH1 gene; SNPnon, all nonsynonymous SNPs of the RH1 gene; (s), a polymorphic synonymous SNP of the RH1 gene; (n), a polymorphic nonsynonymous SNP of the RH1 gene.

three individual positively selected sites in $R H 1$, including AA299, which was verified as a true tuning site for rhodopsin (Table 5).

Moreover, selective forces most probably influence the rhodopsin gene of $P$. minutus, as the samples did not group according to geographical or historical proximity with regards to $R H 1$ variation (Hemmer-Hansen et al. 2007). Strong discrepancies were found between the distribution of the variation at RH1 and the phylogeographic pattern of the sand goby based on the distribution of the variation at the mtDNA Cyt $b$ gene (Larmuseau et al. 2009) and nuclear allozyme (Stefanni et al. 2003) and microsatellite markers (M. H. D. Larmuseau, unpublished data). Samples of the northern Baltic Sea and Mediterranean Sea carry a similar allelic profile of the RH1 gene (Fig. 3; Tables 2 and 3), although historically the Mediterranean P. minutus individuals belong to a different phylogeographic mtDNA Clade (MS-Clade) than the Atlantic and Baltic sand gobies (AO-Clade) (Larmuseau et al. 2009). The RH1 gene was also congruent between sand gobies from the Iberian Peninsula and the Irish Sea-Bay of Biscay. However, the Iberian sand gobies belong to a different historical unit (IB-Group) compared with the North Atlantic gobies (NA-Group), which includes all the populations from the Bay of Biscay to the northern Baltic. Additionally, distributions of the RH1 and microsatellite variation were statistically significant different from each other (Table 6). No convincing evidence was found for non-neutrality of any of the microsatellites used to represent the neutral baseline. In contrast, each SNP of the
RH1 gene was clearly identified as an outlier locus in comparison with the microsatellite markers. Therefore, random processes may be ruled out to explain the functional differentiation on the RH1 gene between the different sand goby populations.

\section{The link between functional variation on RH1 and environmental light climate}

The significant discrepancies at various levels between the distribution of neutral markers and $R H 1$ gene data suggest that its variation is influenced by the optical environment instead of genetic drift. Differences in optical characteristics clustered the sampling locations into three groups: the Mediterranean Sea, Iberian Peninsula, the Bay of Biscay and Irish Sea (VMS, AAO, GOA and WIS) with a mainly blue light climate; the southern Baltic and North Sea (PBS and NBS) with greener water and the northern Baltic Sea (TBS) with water with the highest WMTL values (Fig. 1, Jerlov 1976). In general, these robust differences in environmental light transmittance correspond well with the differences in the absorbance spectra of the retinal rods (Jokela et al. 2003) and with functional variation at the $R H 1$ gene. The blue-shift of the $\lambda_{\max }$ values of the dim-light receptors and the highest frequency of the Ala299Ser substitution in the Bay of Biscay, Irish Sea and the Iberian Peninsula is characteristic for offshore blue water. The red-shift of the $\lambda_{\max }$ values of the rods and the highest frequency of Phe261Tyr substitution in the northern Baltic might be an adaptation to the red-shifted light condition in this region. One remark- 
able observation is that the individuals of the Mediterranean Sea clustered with the northern Baltic samples based on the RH1 variation. In the Mediterranean Sea, coastal lagoons play an important role in the life cycle of sand gobies as nurseries and feeding sites (Bouchereau \& Guelorget 1998), whereas this is not the case for Atlantic sand gobies (Guelinckx et al. 2008). These lagoons, which are not included in Fig. 1, are characterized by a much higher turbidity than offshore (Poizat et al. 2004). Such conditions are thought to require spectral adaptations similar to those in the Northern Baltic.

\section{Conclusion}

The three conditions to demonstrate local adaptation at the rhodopsin gene of the sand goby are fulfilled. First, functional polymorphism was observed in the RH1 gene. Then, it was demonstrated that population differentiation at the RH1 gene was because of selection. Finally, a correlation was found between RH1 variation and the specific spectral characteristics of the habitat environment of the sand goby. Therefore, there are good indicators for local adaptation of the rhodopsin gene in Pomatoschistus minutus. Further molecular research with a higher sampling resolution in space and time is required to disentangle the temporal variability of the RH1 polymorphism and the small-scale differentiation on the RH1 gene for P. minutus inside the various marine systems.

The hypothesis that sand gobies are evolutionary adapted to their optical environment implies that rapid changes in optical habitat characteristics may have negative consequences. For example, increased water turbidity by algal blooms in the highly polluted Baltic Sea negatively influenced sexual behaviour of fishes with a visual mating system. Cases have been documented for sand goby (Järvenpää \& Lindström 2004) and threespined stickleback (Gasterosteus aculeatus) (Engström-Öst \& Candolin 2007; Candolin et al. 2008). Water quality of lagoonal and coastal waters can be influenced by anthropogenic changes in the nutrient load and by climatic factors. Therefore, if temperature continues to rise, spectral transmission of the water may shift with temperature (Archer et al. 2001). A marine monitoring program for water clarity and optical properties is therefore recommended, not only to consider their effect on primary productivity but also because of their direct influence on the visual capacity of the fish community (Aksnes 2007) and other organisms.

\section{Acknowledgements}

We thank the following persons who generous provided samples: Pilar Drake (CSIC, Spain), Maria Järvi-Laturi (University of Helsinki, Finland), Kai Lindström (Åbo Akademi University, Finland), Katarzyna Waligóra-Borek (University of Gdańsk, Poland), Ian McCarthy (University of Wales, Bangor, UK), Mario Lepage (Ifremer, France), Jef Guelinckx (Flemish Goby Consortium, Belgium) \& Alain Crivelli (Station Biologique de la Tour du Valat, France). We also thank the 'Marine Genomics Europe' Network of excellence, subject editor Michael Hansen, five anonymous referees and Anne Christine Utne-Palm, Luisa Orsini, Gregory Maes, Hendrik Larmuseau, Bart Hellemans \& Erika Souche for useful discussions and technical assistance. The first author received a PhD-fellowship of the Institute for the Promotion of Innovation through Science and Technology in Flanders (IWT-Vlaanderen). The second author received a postdoctoral fellowship of Fund for Scientific Research-Flanders (FWO-Vlaanderen). This study was part of the WESTBANKS project financed by the Belgian Federal Office for Scientific, Technical and Cultural Affairs (contract $\mathrm{nr}$ $\mathrm{SD} / \mathrm{BN} / 01 \mathrm{~A})$.

\section{References}

Aarnio K, Bonsdorff E (1993) Seasonal-variation in abundance and diet of the sand goby Pomatoschistus minutus (Pallas) in a northern Baltic archipelago. Ophelia, 37, 19-30.

Aksnes DL (2007) Evidence for visual constraints in large marine fish stocks. Limnology and Oceanography, 52, 198-203.

Anisimova M, Nielsen R, Yang ZH (2003) Effect of recombination on the accuracy of the likelihood method for detecting positive selection at amino acid sites. Genetics, 164, 1229-1236.

Antao T, Lopes A, Lopes RJ, Beja-Pereira A, Luikart G (2008) LOSITAN: a workbench to detect molecular adaptation based on a $F_{S T}$ outlier method. BMC Bioinformatics, 9, 323.

Archer SN, Lythgoe JN, Hall L (1992) Rod opsin cDNA sequence from the sand goby (Pomatoschistus minutus) compared with those of other vertebrates. Proceedings of the Royal Society of London. Series B: Biological Sciences, 248, 19-25.

Archer S, Hirano J, Vallerga S (2001) The effects of variability of marine ecosystems on the visual sensitivity of fish. Archo Oceanography Limnology, 22, 119-126.

Asenjo AB, Rim J, Oprian DD (1994) Molecular determinants of human red/green color discrimination. Neuron, 12, 11311138 .

Audzijonyte A, Pahlberg J, Väinölä R, Lindstrom M (2005) Spectral sensitivity differences in two Mysis sibling species (Crustacea, Mysida): adaptation or phylogenetic constraints? Journal of Experimental Marine Biology and Ecology, 325, 228239.

Bamshad M, Wooding SP (2003) Signatures of natural selection in the human genome. Nature Reviews Genetics, 4, 99-111A.

Beaumont MA, Nichols RA (1996) Evaluating loci for use in the genetic analysis of population structure. Proceedings of the Royal Society of London. Series B: Biological Sciences, 263, 16191626.

Belkhir K, Borsa P, Chikhi L, Raufaste N, Bonhomme F (2004) geNetIX 4.05, Logiciel Sous WindowsTM pour la Génétique Des Populations. Université de Montpellier II, Montpellier, France.

Bouchereau JL, Guelorget O (1998) Comparison of three Gobiidae (Teleostei) life history strategies over their geographical range. Oceanologica Acta, 21, 503-517. 
Bowmaker JK (1995) The visual pigments of fish. Progress in Retinal and Eye Research, 15, 1-31.

Candolin U, Engström-Öst J, Salesto T (2008) Human-induced eutrophication enhances reproductive success through effects on parenting ability in sticklebacks. Oikos, 117, 459-465.

Canino MF, O'Reilly PT, Hauser L, Bentzen P (2005) Genetic differentiation in walleye pollock (Theragra chalcogramma) in response to selection at the pantophysin (Pan I) locus. Canadian Journal of Fisheries and Aquatic Sciences, 62, 25192529.

Chen WJ, Bonillo C, Lecointre G (2003) Repeatability of clades as a criterion of reliability: a case study for molecular phylogeny of Acanthomorpha (Teleostei) with larger number of taxa. Molecular Phylogenetics and Evolution, 26, 262-288.

Clarke KR (1993) Nonparametric multivariate analyses of changes in community structure. Australian Journal of Ecology, 18, 117-143.

Clement M, Posada D, Crandall KA (2000) TCS: a computer program to estimate gene genealogies. Molecular Ecology, 9, 1657-1659.

Conover DO, Clarke LM, Munch SB, Wagner GN (2006) Spatial and temporal scales of adaptive divergence in marine fishes and the implications for conservation. Journal of Fish Biology, 69, 21-47.

Cowen RK, Lwiza KMM, Sponaugle S, Paris CB, Olson DB (2000) Connectivity of marine populations: open or closed? Science, 287, 857-859.

Dann SG, Allison WT, Levin DB, Taylor JS, Hawryshyn CW (2004) Salmonid opsin sequences undergo positive selection and indicate an alternate evolutionary relationship in Oncorhynchus. Journal of Molecular Evolution, 58, 400-412.

Debes PV, Zachos FE, Hanel R (2008) Mitochondrial phylogeography of the European sprat (Sprattus sprattus L., Clupeidae) reveals isolated climatically vulnerable populations in the Mediterranean Sea and range expansion in the northeast Atlantic. Molecular Ecology, 17, 3873-3888.

Ehrenberg SZ, Ejdung G (2008) Daily activity pattern of the sand goby, Pomatoschistus minutus (Pisces), at low light intensity. Hydrobiologia, 603, 129-137.

Engström-Öst J, Candolin U (2007) Human-induced water turbidity alters selection on sexual displays in sticklebacks. Behavioral Ecology, 18, 393-398.

Excoffier L, Laval G, Schneider S (2005) ARLEQUIN ver.3.0: an integrated software package for population genetics data analysis. Evolutionary Bioinformatics Online, 1, 47-50.

Fasick JI, Robinson PR (1998) Mechanism of spectral tuning in the dolphin visual pigments. Biochemistry, 37, 433-438.

Gower JC (1975) Generalized Procrustes analysis. Psychometrika, 40, 33-51.

Guelinckx J, Maes J, Geysen B, Ollevier F (2008) Estuarine recruitment of a marine goby reconstructed with an isotopic clock. Oecologia, 157, 41-52.

Hamerlynck O (1990) The identification of Pomatoschistus minutus (Pallas) and Pomatoschistus lozanoi (de Buen) (Pisces, Gobiidae). Journal of Fish Biology, 37, 723-728.

Hargrave PA, McDowell JH (1992) Rhodopsin and phototransduction-a model system for G-protein-linked receptors. FASEB Journal, 6, 2323-2331.

Healey MC (1971) Distribution and abundance of sand gobies, Gobius minutus, in Ythan estuary. Journal of Zoology, 163, 177229
Hemmer-Hansen J, Nielsen EE, Frydenberg J, Loeschcke V (2007) Adaptive divergence in a high gene flow environment: $\mathrm{Hsc70}$ variation in the European flounder (Platichthys flesus L.). Heredity, 99, 592-600.

Hunt DM, Fitzgibbon J, Slobodyanyuk SJ, Bowmaker JK (1996) Spectral tuning and molecular evolution of rod visual pigments in the species flock of cottoid fish in Lake Baikal. Vision Research, 36, 1217-1224.

Hunt DM, Dulai KS, Partridge JC, Cottrill P, Bowmaker JK (2001) The molecular basis for spectral tuning of rod visual pigments in deep-sea fish. Journal of Experimental Biology, 204, 3333-3344.

Hunt DM, Carvalho LS, Cowing JA et al. (2007) Spectral tuning of shortwave-sensitive visual pigments in vertebrates. Photochemistry and Photobiology, 83, 303-310.

Jackson DA (1995) Protest-a Procrustean randomization test of community environment concordance. Ecoscience, 2, 297303.

Järvenpää M, Lindström K (2004) Water turbidity by algal blooms causes mating system breakdown in a shallow-water fish, the sand goby Pomatoschistus minutus. Proceedings of the Royal Society of London. Series B: Biological Sciences, 271, 23612365.

Jerlov N (1976) Marine Optics. Elsevier, Amsterdam, 231 pp.

Jokela M, Vartio A, Paulin L, Fyhrquist-Vanni N, Donner K (2003) Polymorphism of the rod visual pigment between allopatric populations of the sand goby (Pomatoschistus minutus): a microspectrophotometric study. Journal of Experimental Biology, 206, 2611-2617.

Jukes TH, Cantor CR (1969) Evolution of protein molecules. In: Mammalian Protein Metabolis (ed. Munro HN), pp. 21-132. Academic Press, New York.

Knutsen H, Jorge PE, Andre C, Stenseth NC (2003) Fine-scaled geographical population structuring in a highly mobile marine species: the Atlantic cod. Molecular Ecology, 12, 385-394.

Larmuseau MHD, Hellemans B, Van Houdt JKJ, Volckaert FAM (2007) Development and characterization of nine polymorphic microsatellite markers in the sand goby Pomatoschistus minutus (Gobiidae). Molecular Ecology Notes, 7, 147-149.

Larmuseau MHD, Guelinckx J, Hellemans B, Van Houdt JKJ, Volckaert FAM (2008) Fast PCR-RFLP method facilitates identification of Pomatoschistus species in the North Atlantic. Journal of Applied Ichthyology, 24, 342-344.

Larmuseau MHD, Van Houdt JKJ, Guelinckx J, Hellemans B, Volckaert FAM (2009) Distributional and demographic consequences of Pleistocene climate fluctuations for a marine demersal fish in the NE Atlantic. Journal of Biogeography, 36, 1138-1151.

Legendre P (2000) Comparison of permutation methods for the partial correlation and partial Mantel tests. Journal of Statistical Computation and Simulation, 67, 37-73.

Lindström M (2000) Eye function of Mysidacea (Crustacea) in the northern Baltic Sea. Journal of Experimental Marine Biology and Ecology, 246, 85-101.

Luttikhuizen PC, Campos J, Van Bleijswijk J, Peijnenburg KTCA, van der Veer HW (2008) Phylogeography of the common shrimp, Crangon crangon (L.) across its distribution range. Molecular Phylogenetics and Evolution, 46, 1015-1030.

Mantel N (1967) The detection of disease clustering and generalised regression approach. Cancer Research, 27, 209220 . 
Miller PJ (1986) Gobiidae. In: Fishes of the North-Eastern Atlantic and Mediterranea (eds Whitehead PJP, Bauchot M-L, Hureau JC, Nielsen J, Tortononese E), pp. 1019-1085. UNESCO, Paris.

Nei M, Gojobori T (1986) Simple methods for estimating the numbers of synonymous and nonsynonymous nucleotide substitutions. Molecular Biology and Evolution, 3, 418-426.

Nielsen R, Yang Z (1998) Likelihood models for detecting positively selected amino acid sites and applications to the HIV-1 envelope gene. Genetics, 148, 929-936.

Oksanen J, Kindt R, Legendre P, O'Hara RB (2007) VEGAN: Community ecology package, version 1.8-5. Available from: http://cran.r-project.org/.

Pampoulie C, Stefansson MO, Jorundsdottir TD, Danilowicz BS, Danielsdottir AK (2008) Recolonization history and largescale dispersal in the open sea: the case study of the North Atlantic cod, Gadus morhua L. Biological Journal of the Linnean Society, 94, 315-329.

Park JH, Scheerer P, Hofmann KP, Choe H-W, Ernst OP (2008) Crystal structure of the ligand-free G-protein-coupled receptor opsin. Nature, 454, 183-187.

Poizat G, Rosecchi E, Chauvelon P, Contournet P, Crivelli AJ (2004) Long-term fish and macro-crustacean community variation in a Mediterranean lagoon. Estuarine Coastal and Shelf Science, 59, 615-624.

Rozas J, Sanchez-DelBarrio JC, Messeguer X, Rozas R (2003) DnaSP, DNA polymorphism analyses by the coalescent and other methods. Bioinformatics, 19, 2496-2497.

Rozen S, Skaletsky HJ (1998) Primer 3. Available from: http:// frodo.wi.mit.edu/primer3/

Ruzzante DE, Taggart CT, Cook D (1998) A nuclear DNA basis for shelf- and bank-scale population structure in northwest Atlantic cod (Gadus morhua): Labrador to Georges Bank. Molecular Ecology, 7, 1663-1680.

Sherman CDH, Ayre DJ (2008) Fine-scale adaptation in a clonal sea anemone. Evolution, 62, 1373-1380.

Stefanni S, Gysels ES, Volckaert FAM, Miller PJ (2003) Allozyme variation and genetic divergence in the sand goby, Pomatoschistus minutus (Teleostei: Gobiidae). Journal of the Marine Biological Association of the United Kingdom, 83, 11431149.

Stephens M, Donnelly P (2003) A comparison of Bayesian methods for haplotype reconstruction from population genotype data. American Journal of Human Genetics, 73, 11621169.

Stephens M, Smith NJ, Donnelly P (2001) A new statistical method for haplotype reconstruction from population data. American Journal of Human Genetics, 68, 978-989.

Tamura K, Dudley J, Nei M, Kumar S (2007) MEGA4: molecular evolutionary genetics analysis (MEGA) software version 4.0. Molecular Biology and Evolution, 24, 1596-1599.

Thetmeyer H (1997) Diel rhythms of swimming activity and oxygen consumption in Gobiusculus flavescens (Fabricius) and Pomatoschistus minutus (Pallas) (Teleostei: Gobiidae). Journal of Experimental Marine Biology and Ecology, 218, 187-198.

Yang ZH, Wong WSW, Nielsen R (2005) Bayes emirical Bayes inference of amino acid sites under positive selection. Molecular Biology and Ecology, 22, 1107-1118.
Yang Z (2007) PAML4: phylogenetic analysis by maximum likelihood. Molecular Biology and Evolution, 24, 1586-1591.

Yang Z, Nielsen R, Goldman N, Pedersen A-MK (2000) Codonsubstitution models for heterogeneous selection pressure at amino acid sites. Genetics, 155, 431-449.

Yokoyama S (2000) Molecular evolution of vertebrate visual pigments. Progress in Retinal and Eye Research, 19, 385-419.

Yokoyama S, Takenaka N (2004) The molecular basis of adaptive evolution of squirrelfish rhodopsins. Molecular Biology and Evolution, 21, 2071-2078.

Yokoyama R, Knox BE, Yokoyama S (1995) Rhodopsin from the fish, Astyanax-role of tyrosine-261 in the red shift. Investigative Ophthalmology \& Visual Science, 36, 939-945.

Yokoyama S, Tada T, Yamato T (2007) Modulation of the absorption maximum of rhodopsin by amino acids in the Cterminus. Photochemistry and Photobiology, 83, 236-241.

Zane L (2007) Adaptive divergence overcoming gene flow. Heredity, 99, 565-566.

M.H.D.L. defended his $\mathrm{PhD}$ on the relationship between phylogeography and local adaptation in marine fish. J.A.M.R. studies the ecology and evolution of three-spined stickleback. K.R.'s research interests are in marine optics and optical remote sensing. J.K.J.V.H. is interested in conservation genetics and genomic approaches. F.A.M.V.'s research comprises the population genetics and evolutionary biology of marine and freshwater fishes and their parasites.

\section{Supporting information}

Additional supporting information may be found in the online version of this article.

Table S1 Rhodopsin haplotypes and their geographical distribution in Pomatoschistus minutus. The numbers of haplotypes reconstructed with a probability $\geq 95 \%$ (estimated using PHASE 2.0.2) are listed in bold. The numbers of haplotypes that were nonsignificantly reconstructed are given in italic and between brackets. Dots indicate homology with haplotype RhP1. For site abbreviations, see Table 1

Table S2 Nucleotide polymorphisms at the RH1 gene in seven sand goby populations. Dots indicate homology with the reference sequence (Accession no. X62405 or haplotype RhP1). AA numbers are listed for the nonsynonymous mutations, which are listed in bold. For site codes, see Table 1

Appendix S1 Estimates of wavelengths of maximally transmitted light for European seas: theory and description of method.

Please note: Wiley-Blackwell is not responsible for the content or functionality of any supporting information supplied by the authors. Any queries (other than missing material) should be directed to the corresponding author for the article. 